\title{
Painful sickle cell crises precipitated by stopping prophylactic exchange transfusions
}

\author{
AJ KEIDAN,* SS MARWAH,* GR VAUGHAN, $\dagger$ IM FRANKLIN, $\dagger$ J STUART* \\ From the Departments of Haematology, ${ }^{*}$ Medical School, University of Birmingham, and the $†$ Queen Elizabeth \\ Hospital, Birmingham
}

SUMMARY A patient with homozygous sickle cell disease showed a reduced incidence of painful crises as a result of regular exchange transfusion, but on three occasions when transfusion treatment was interrupted, a painful crisis occurred. Onset of painful crisis was associated with raised packed cell volume (PCV) or percentage of haemoglobin S (HbS\%), or both. Measurement of whole blood viscosity using in vitro mixtures of blood group compatible normal (AA) and sickle (SS) cells showed that above an $\mathrm{HbS}$ of $25 \%$ any increase in PCV caused a disproportionate increase in whole blood viscosity. These clinical observations and laboratory data suggest that when regular exchange transfusions are terminated both $\mathrm{HbS} \%$ and PCV should be carefully monitored. Prophylactic venesection should be considered for patients who maintain their PCV after transfusion as $\mathrm{HbS} \%$ rises.

The viscosity of whole blood is determined by its packed cell volume (PCV), plasma viscosity, and the deformability and aggregation of its erythrocytes. The rheological contribution of each of these components to whole blood viscosity can be measured individually, ${ }^{12}$ but all of them must be taken into account in clinical studies as a change in one may offset or add to the effects of another. This is particularly important in rheological studies of sickle cell disease. In the steady state of sickle cell disease the viscosity of oxygenated sickle (SS) blood is lower than that in normal (AA) controls because the rheological benefit of anaemia ${ }^{3}$ more than compensates for the poor deformability of SS cells. Exchange transfusions will lower the whole blood viscosity of patients with sickle cell disease (assuming no change in PCV) as the transfused AA erythrocytes are more deformable. ${ }^{4}$ If, however, the PCV is allowed to increase whole blood viscosity will consequently rise above normal. ${ }^{5}$ For this reason, exchange, rather than top up, transfusion is often preferred. ${ }^{6}$

On stopping long term prophylactic transfusions in sickle cell disease, it is assumed that the rheological effect of the rising percentage of haemoglobin $\mathrm{S}$ $(\mathrm{HbS} \%)$ is offset by the falling PCV, so that whole blood viscosity does not increase. In some cases, how-

Accepted for publication 18 November 1986 ever, endogenous erythropoesis may not be fully suppressed by the transfusion programme. Such patients may maintain their post-transfusion PCV for several weeks and thus are at rheological risk of vascular occlusion as their $\mathrm{HbS} \%$ increases during this transitional period. This rheological hazard of stopping prophylactic transfusions has not been adequately documented.

\section{Case reports}

A 24 year old male graduate with homozygous sickle cell disease had suffered frequent and severe painful crises (12 in 27 months), causing considerable disruption to his school and college studies. He was therefore started on prophylactic exchange transfusions from December 1983. Having successfully completed undergraduate studies in June 1985, transfusions were stopped. By this time his serum ferritin concentration had increased to $3188 \mu \mathrm{g} / \mathrm{l}$ (reference range 15-300). In August 1985, 10 weeks after the last transfusion, he was admitted in painful crisis affecting the right shoulder, elbow, and knee. Despite analgesics and intravenous fluids he failed to improve. Exchange transfusions were carried out on days four and seven after which he recovered quickly. Having relapsed so soon after discontinuation of regular transfusions, these were restarted on a prophylactic basis for a further six months.

During 18 months of prophylactic transfusions 
(December 1983 to June 1985), the patient required five admissions for painful crises (table 1). Two of these episodes (crises 2 and 4) occurred when transfusion was inadvertently delayed, two others (crises 1 and 3) occurred when both $\mathrm{HbS} \%$ and PCV were relatively high, and one (crisis 5) was precipitated by staphylococcal pneumonia. The data suggested that a crisis was more likely to occur when $\mathrm{HbS} \%$ or $\mathrm{PCV}$, or both, were raised and led us to investigate the individual and combined effects of $\mathrm{HbS} \%$ and PCV on whole blood viscosity in vitro.

\section{Methods}

Venous blood from two healthy AA subjects and two SS patients in the steady state was anticoagulated with $\mathrm{K}_{2}$ EDTA $(1.5 \mathrm{mg} / \mathrm{ml}$ blood) and tested within four hours of venepuncture. The $\mathrm{HbS} \%$ was obtained using paper electrophoresis and elution ${ }^{7}$ or agarose gel ( $\mathrm{pH} \mathrm{8.6)} \mathrm{electrophoresis} \mathrm{and} \mathrm{scanning} \mathrm{densi-}$ tometry (Beckman Paragon Electrophoresis System, Beckman Instruments, Brea, California, USA). Packed cell volumes were determined by microhaematocrit centrifugation of oxygenated red cells for 10 minutes at $13000 \mathrm{~g}$ (Hawskley and Sons Ltd, Lancing, Sussex).

ABO and Rhesus matched AA and SS blood samples were tested for compatibility at room temperature using a low ionic strength saline two way cross match. Whole blood viscosity was measured at $25^{\circ} \mathrm{C}$ and ambient oxygen tension using a Contraves low shear 30 rheometer (Contraves Industrial Products Ltd, Ruislip, Middlesex) at a high shear rate of 128.5 seconds $^{-1}$.

Mixtures of compatible AA and oxygenated SS whole blood were made to give final concentrations of $0,25,50,75$, and $100 \%$ HbS. For each $\mathrm{HbS} \%$, samples of differing PCV (range $0 \cdot 20-0 \cdot 70$ ) were obtained by the addition or removal of plasma. The viscosity of each sample was then measured and a regression line of $\log$ viscosity against PCV drawn for each $\mathrm{HbS} \%$.

Table 1 Clinical and haematological details at time of hospital admission for painful crisis (crises 1-5 during, and crisis 6 after, 18 months of prophylactic exchange transfusions) compared with those obtained in asymptomatic steady state value

\begin{tabular}{lll}
\hline Clinical details & $H b S \%$ & $P C V$ \\
\hline Mean (SEM) pretransfusion value when & & \\
$\quad$ patient asymptomatic (n = 10) & $47 \cdot 1(3 \cdot 3)$ & $0.34(0 \cdot 001)$ \\
Crisis 1 & 61 & 0.37 \\
Crisis 2-transfusion delay & -50 & 0.31 \\
Crisis 3 & 60 & 0.39 \\
Crisis 4 transfusion delay & 53 & 0.31 \\
Crisis 5-staphylococcal pneumonia & 0.32 \\
Crisis 6-transfusion programme stopped & 59 & 0.33 \\
\hline
\end{tabular}

Using the five regression lines, viscosity values at PCVs of $0.15,0.25,0.35$, and 0.45 were estimated for each $\mathrm{HbS} \%$. As values for whole blood viscosity are commonly expressed in relation to a PCV of 0.45 , the viscosity value for AA blood $(0 \% \mathrm{HbS})$ at a PCV of 0.45 was assigned an arbitrary reference value of $100 \%$, and all other viscosity values were expressed as a percentage of this value.

\section{Results}

The regression line relating log viscosity to PCV was steeper for SS (slope 1.512) than for AA (slope 1.323) blood so that, at the same PCV, the viscosity of SS blood was always higher (figure). Table 2 shows the effects of variation in $\mathrm{HbS} \%$ and $\mathrm{PCV}$ on whole blood viscosity. As the observed regression lines of $\log$ viscosity against $\mathrm{PCV}$ for each $\mathrm{HbS} \%(25,50$, and $75 \%$ ) were found to overlie the lines predicted from the proportional summation of appropriate values from the $0 \%$ (AA) and $100 \%$ (SS) regression lines, we were able to construct a table showing the predicted effect on whole blood viscosity over a wider range of $\mathrm{HbS} \%$ values (table 1 ). As the $\mathrm{HbS} \%$ increased a given rise in PCV had a larger effect on whole blood viscosity.

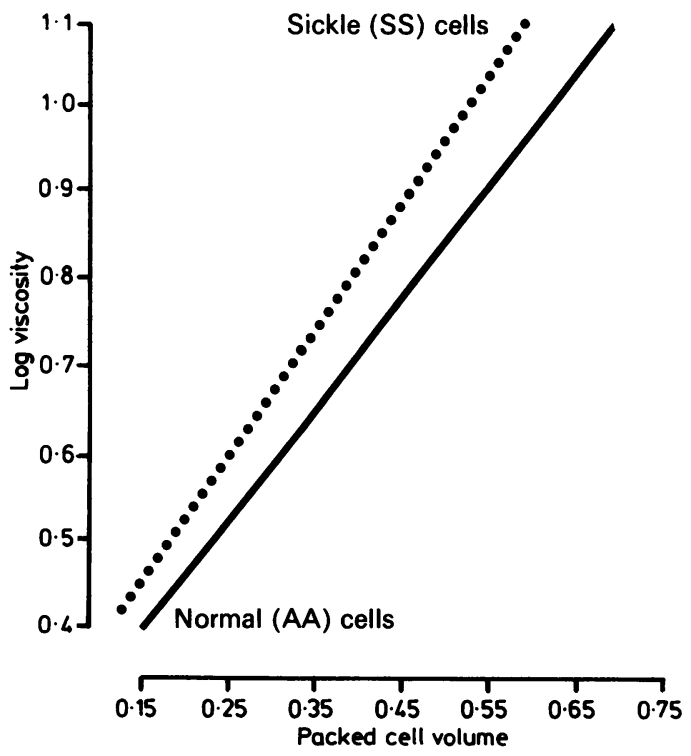

Figure Regression lines relating log whole blood viscosity to packed cell volume for one SS $(y=1.512 x+0 \cdot 232)$ and one $A A(y=1 \cdot 323 x+0 \cdot 213)$ sample. 
Table 2 Observed and predicted effects of $\mathrm{PCV}$ and $\mathrm{HbS} \%$ on whole blood viscosity at ambient oxygen tension and high shear*

\begin{tabular}{|c|c|c|c|c|}
\hline & 0.15 & 0.25 & $0 \cdot 35$ & 0.45 \\
\hline 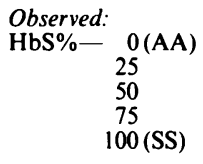 & $\begin{array}{l}44 \cdot 0 \\
41 \cdot 5 \\
46 \cdot 4 \\
48 \cdot 8 \\
46 \cdot 3\end{array}$ & $\begin{array}{l}57 \cdot 7 \\
56 \cdot 1 \\
64 \cdot 0 \\
66 \cdot 9 \\
65 \cdot 5\end{array}$ & $\begin{array}{l}76.0 \\
76.2 \\
88.9 \\
91.6 \\
92.7\end{array}$ & $\begin{array}{l}100.0 \\
103.4 \\
123.4 \\
125.3 \\
131.0\end{array}$ \\
\hline $\begin{array}{r}\text { Predicted: } \\
\text { HbS\% }-25 \\
30 \\
35 \\
40 \\
45 \\
50 \\
55 \\
60 \\
65 \\
70 \\
75\end{array}$ & $\begin{array}{l}44 \cdot 6 \\
44 \cdot 7 \\
44 \cdot 8 \\
44 \cdot 9 \\
45 \cdot 1 \\
45 \cdot 2 \\
45 \cdot 3 \\
45 \cdot 4 \\
45 \cdot 5 \\
45 \cdot 6 \\
45 \cdot 7\end{array}$ & $\begin{array}{l}59 \cdot 8 \\
60 \cdot 1 \\
60 \cdot 5 \\
60 \cdot 9 \\
61 \cdot 3 \\
61 \cdot 6 \\
62 \cdot 1 \\
62 \cdot 4 \\
62 \cdot 8 \\
63 \cdot 2 \\
63 \cdot 6\end{array}$ & $\begin{array}{l}80 \cdot 2 \\
81 \cdot 0 \\
81 \cdot 8 \\
82 \cdot 7 \\
83 \cdot 4 \\
84 \cdot 2 \\
85 \cdot 2 \\
86 \cdot 0 \\
87 \cdot 3 \\
87 \cdot 7 \\
88 \cdot 6\end{array}$ & $\begin{array}{l}107.8 \\
109.3 \\
111.0 \\
112.6 \\
114.1 \\
115.5 \\
117.3 \\
118.6 \\
120.4 \\
121.9 \\
123.5\end{array}$ \\
\hline
\end{tabular}

*Viscosity results (means for two experiments) expressed as

percentage of $100 \%$ value assigned to AA blood at PCV of 0.45 .

\section{Discussion}

Whole blood viscosity, because of its dependence on $\mathrm{PCV}$, is of particular value in monitoring the rheological effects of exchange transfusion in sickle cell disease. $^{8}$ The effect of PCV on whole blood viscosity is well documented for both $\mathrm{AA}^{9}$ and $\mathrm{SS}^{10}$ blood, and the beneficial effect of dilution with AA cells on the rheology of SS cells has been shown in vitro ${ }^{411}$ and borne out by clinical observations. ${ }^{1213}$ An increase in $\mathrm{PCV}$ and a decrease in $\mathrm{HbS} \%$ have opposing rheological effects on whole blood viscosity, but the rheological balance between the two variables has not been formally investigated.

Using in vitro mixtures of varying $\mathrm{HbS} \%$, we have shown the separate and combined effects of PCV and $\mathrm{HbS} \%$ on whole blood viscosity at ambient oxygen tension. As the $\mathrm{HbS}$ concentration increased there was a progressive rise in whole blood viscosity, the effect being more pronounced at higher PCV values. All whole blood viscosity values $(0-100 \% \mathrm{HbS})$ at a PCV of 0.35 were below that of AA blood at a PCV of 0.45 , emphasising the major influence of PCV on whole blood viscosity for oxygenated samples. On deoxygenation, however, the whole blood viscosity of SS blood increases disproportionately, ${ }^{3}$ with the $\mathrm{HbS} \%$ then becoming the major determinant of whole blood viscosity. Thus in vivo the combination of a relatively high $\mathrm{HbS} \%$ and PCV is particularly detrimental to blood rheology in patients with sickle cell disease.

Although a rheologically "critical" value for whole blood viscosity in sickle cell disease has not been defined, most clinicians perform exchange, rather than top up, transfusions to avoid a rise in PCV. A long term reduction of $\mathrm{HbS} \%$ by this means is accepted management for patients with sickle cell disease who experience cerebrovascular accidents, episodes of chest syndrome, or repeated painful crises. ${ }^{6}$ The problem is when to stop treatment, as there have been reports of cerebral vaso-occlusive episodes ${ }^{14}$ occurring when transfusions have ceased, and long term transfusions may lead to iron overload ${ }^{15}$ unless chelation treatment is also given. Many patients are unwilling to stop transfusions, however, for fear of recurrence of painful crises. If a painful crisis does occur as treatment is withdrawn this may lead to reinstitution of transfusions and reinforce patient dependence. Careful monitoring of both PCV and $\mathrm{HbS} \%$ at the time transfusions are discontinued is therefore recommended. If the rising $\mathrm{HbS} \%$ is not sufficiently offset by a fall in PCV then limited venesection will prevent a rise in whole blood viscosity, which may otherwise precipitate painful crisis. This approach should allow the patient to be successfully and uneventfully weaned off treatment by transfusion.

AJK is funded by Action Research for the Crippled Child.

\section{References}

1 Chien S. Principles and techniques for assessing erythrocyte deformability. Blood Cells 1977;3:71-99.

2 Stuart J. Erythrocyte rheology. J Clin Pathol 1985;38:965-77.

3 Chien S. Rheology of sickle cells and erythrocyte content. Blood Cells 1977;3:283-303.

4 Anderson R, Cassell M, Mullinax GL, Chaplin H. Effect of normal cells on viscosity of sickle cell blood. Arch Intern Med 1963;111:286-94.

5 Jan K, Usami S, Smith JA. Effects of transfusion on rheological properties of blood in sickle cell anemia. Transfusion 1982;22:17-20.

6 Serjeant GR. Blood transfusion in sickle cell disease. In: Das PC, Smit Sibinga CTh, Halie MR, eds. Supportive therapy in haematology. Dordrecht: Martinus Nijhoff, 1985:199-208.

7 Dacie JV, Lewis SM. Practical haematology. 6th ed. Edinburgh: Churchill Livingstone, 1984.

8 Stuart J. Sickle cell disease and vascular occlusion-rheological aspects. Clin Hemorheol 1984;4:193-207.

9 Wells RE, Denton R, Merrill EW. Measurement of viscosity of biologic fluids by cone plate viscometer. J Lab Clin Med 1961;57:646-56.

10 Self F, McIntire LV, Zanger B. Rheological evaluation of hemoglobin $\mathrm{S}$ and hemoglobin $\mathrm{C}$ hemoglobinopathies. J Lab Clin Med 1977;89:488-97.

11 Lessin LS, Kurantsin-Mills J, Klug P, Weems HB. Determination of rheologically optimal mixtures of AA and SS erythrocytes for transfusion. Prog Clin Biol Res 1978;20:123-34.

12 Miller DM, Winslow RM, Klein HG, Wilson KC, Brown FL, Statham NJ. Improved exercise performance after exchange transfusion in subjects with sickle cell anemia. Blood 1980;56:1127-31.

13 Van de Pette JEW, Pearson TC, Slater NGP. Exchange transfusion in life-threatening sickling crises. $J$ Roy Soc Med 1982;75:777-80.

14 Kruse J, White DS. Sickle cell crisis after discontinuation of periodic transfusion therapy. Mo Med 1983;80:297-8.

15 Davies S, Henthorn JS, Brozovic M. Effect of blood transfusion on iron status in sickle cell anaemia. Clin Lab Haematol 1984;6:17-22.

Requests for reprints to: Professor J Stuart, Department of Haematology, The Medical School, University of Birmingham, Vincent Drive, Birmingham B15 2TJ. 